\title{
PROTECTION OF A CONTROL SYSTEM OF A TECHNICAL OBJECT FROM NEGATIVE INFLUENCE OF HUMAN FACTORS BY USING STEGANOGRAPHIC METHODS
}

\author{
OCHRONA SYSTEMU STEROWANIA OBIEKTEM \\ TECHNICZNYM PRZED NEGATYWNYM WPLYWEM \\ CZYNNIKÓW LUDZKICH Z WYKORZYSTANIEM \\ METOD STEGANOGRAFICZNYCH
}

Olesya Afanasyeva

Technics Institute, Pedagogical University in Kraków

\begin{abstract}
It is difficult to avoid influence of human factor on work of complex technical objects, so safety systems of technical objects have to contain tools of analysis and withstanding possible negative influences from the side of service personnel (SP). To withstand negative influence of human factors on work of a complex technical object, this paper proposes to use steganographic methods of hiding certain information. For that, information is hidden from some members of service personnel (SP), for which the corresponding information is negative. Besides, certain information is hidden from some SP members that can block its transfer in the system of controlling the management process. Methods of implementing the steganographic data concealment are to a great degree dependent on the type of a digital environment that is considered to be used. Introducing the information fragments in a graphic digital environment is performed so that they would be invisible in this environment. Thus, it is necessary for values of parameters that characterize the invisibility degree to be consistent with parameters used to describe the environment itself.
\end{abstract}

Keywords: steganographic methods, human factors, steganosystem, complex technical object, information hiding, graphic image, steganosystem parameters

Streszczenie: Trudno uniknać wptywu czynnika ludzkiego na funkcjonowanie złożonych technicznych obiektów, dlatego wszystkie systemy bezpieczeństwa obiektów technicznych powinni zawierać środki analizy $i$ przeciwdziatania możliwemu negatywnemu wplywowi ze strony personelu obstugi (SP). W pracy zaproponowano zastosowanie steganograficznych metod ukrycia informacji pochodzacych od poszczególnych członków grupy SP. Informacja ta jest ukryta przed pozostałymi członkami SP. Wprowadzenie $w$ cyfrowe środowisko informacyjnych fragmentów odbywa się w taki sposób, aby w tym środowisku byty one niewidoczne.

Słowa kluczowe: metody steganograficzne, czynnik ludzki, steganosystem, złożony techniczny obiekt, ukrycie informacji, graficzny obraz, parametry steganosystemy. 
Protection of a control system of a technical object from negative influence... Ochrona systemu sterowania obiektem technicznym przed negatywnym wptywem...

\section{Introduction}

Human factors that lead to negative influence of members of service personnel group (SP) on a complex technical object (CTO), occur in most cases by influence of chosen information types (SI), to which the corresponding members have access or which are used in the process of object control. Another type of a negative influence that human factor leads to is anticipatory blocking of some information that will be called hidden (HI), that is transferred to the service personnel which controls running of a technologic process and is located outside of CTO.

We will assume that on each terminal of a SP member a graphic image is represented of a general state of CTO technologic process, because this representation form is most pleasant. Besides, the terminals also present a set of numeric data with their text interpretations and some texts that represent messages intended for the corresponding participants of controlling the technologic process. Information that has to be sent to members of service personnel located outside of CTO will be called strategic information. Necessity to use steganographic methods is caused by the following factors. Detecting negative information regarding single SP members can be implemented during the process of CTO functioning, and the fact of detection has to be non-accessible for single SP members. Information regarding changes of distributing authority in implementing the control actions caused by detecting negative information is transferred to the category of strategic information. When it becomes known that a SP member is blocking the possibility to send one or another information to the members of the service personnel group located outside of CTO, the protection system implements withstanding the corresponding blockage. This information is hidden by steganographic methods in the environment of data sent from CTO to the SP members of service personnel located outside of CTO. Besides, changes related to changes in status of information packages are invisible for SP members.

In most cases, a graphic image has multiple parameters, most of which have local character and are closely related to semantic content of the corresponding image. Introducing hidden information has to lead to changes, invisible for usual image inspection, in this image.

During introducing the information fragments on the basis of using steganographic methods, one of the most important conditions is ensuring their invisibility during usual, traditional inspection of the corresponding image by a user. Reasoning from the fundamentals, we can assume that for ensuring this condition it is necessary to choose such image fragments, for placing information elements in them, changes in which would be the least noticeable. To these information fragments such image fragments can be related that are the most semantically rich, that can be defined by the corresponding parameters. In order to find the most suitable place for embedding the corresponding information, it is necessary to analyze the graphic image and determine the method of its scanning that is used to search possible places for introducing hidden information. 
Before we review possible operations of image scanning more closely, let us assume that one of important signs of informativeness of a fragment of a graphic image is the value of change gradient of one or another parameter from the totality of parameters that characterize the image. Examples of such parameters can be change in brightness, change in contrast, change in color gamma, etc. Among the parameters $\left\{x_{1}, \ldots, x_{m}\right\}$, that characterize the image, let us choose the parameter $x_{i}$ and build a gradient image field with this parameter. Because change of parameter value is assumed to be discrete and transformations made to parameters are also performed in a discrete form, the gradient field that will be formed will be discrete as well. Because of this, we have to introduce a discrete structure in the image space, within which a gradient field will be built. This discrete structure is defined by an elementary graphic primitive that fills the whole space of a flat graphic image. Such primitives can be regular polyhedrons, for example, these polyhedrons can be regular triangles, squares, hexahedron, etc. Regular figures are chosen as graphic primitives of such type that ensures the full compaction of coverage of graphic image space. If this requirement is not met, some fragments of the graphic image can fall out from the image structure. Structuring of the graphic image space is necessary to ensure possibility of solving the following tasks, caused by processes of implementing the scanning procedures:

- task of choosing the direction of transfer from one image element to another;

- distributing the image space into single fragments that can be chosen not only on the basis of pixel number, but also other signs that can be related to subject interpretation of the image plot;

- task of choosing the coordinate system for structured space where the graphic image is placed.

To implement methods of steganographic hiding of information and, respectively, building steganosystems, we have to solve the task of preliminary distribution of a graphic image into fragments, each of which is analyzed for suitability for placement of elements of the information fragment being hidden. Obviously, this distribution has to be performed according to parameters that characterize the image. These parameters, in their turn, have to be related to parameters that characterize requirements to a steganosystem. One of these parameters characterizes a degree of information relation between fragments of the image.

\section{Analysis of graphic images and determining their scanning methods}

To solve the task of distributing the space into single fragments, the following has to be done:

- choosing the basic geometric primitive to form the structure of space where the image is placed;

- within the scale, as defined by the corresponding primitives, image fragments have to be selected;

- to build rule systems for the trajectory of image scanning to move from one graphic primitive to another; 
Protection of a control system of a technical object from negative influence...

Ochrona systemu sterowania obiektem technicznym przed negatywnym wptywem...

- to form a rule system for building a transition of scanning trajectory between single fragments of a graphic image.

A basic geometric primitive is chosen on the basis of analysis of parameters of an image fragment that represent structures of the corresponding fragments. For instance, if within one image fragment the degree of richness in geometric image components is high, it allows to place in the corresponding fragment more single elements of hidden information. Then the line of image scanning has to go through the bigger number of basic primitives that compose the corresponding fragment.

In this case, let us content ourselves with using regular convex polygons. Formally, structured space of a graphic image can be described as follows:

$$
D(Q, \Theta)=D^{*}(U, B),
$$

where $Q$ and $\Theta$ are axes of a rectangular coordinate system with linear measurement scale, $U$ and $B$ are coordinates of structured space with coordinate measurement scale in units that define the quantity of geometric primitives $u_{i}$ and $b_{i}$, respectively, along the axis that corresponds to $Q$ axis and the one that corresponds to $\Theta$ axis. Thanks to structuring the space, there is a possibility to establish arbitrary order of numbering of single geometric primitives. This order can be defined by various given functions of transforming the primitive numbers, defined by coordinates $Q$ and $\Theta$, into other primitive numbers, which can be written as follows: $u_{i}=f_{1}\left(q_{i}, \vartheta_{j}\right)$ i $b_{i}=f_{2}\left(q_{i}, \vartheta_{j}\right)$.

The rules for moving the segment of a scanning trajectory from one geometric primitive $G_{i}$ to another geometric primitive $G_{j}$ are formed on the basis of using the corresponding image fragment and of using the chosen signs. For the case when such a sign is gradient change and when choosing squares as graphic primitives, the rule system for choosing the next primitive when building the image scanning trajectory can be written as follows:

$$
\begin{aligned}
& P_{1}:\left[\left(h_{i j} \leq h_{i, j+1}\right) \&([(j+1<\max j)]] \rightarrow h_{i, j+1}\right. \\
& \left.P_{2}:\left[\left(h_{i j} \leq h_{i+1, j}\right) \&[(i+1)<\max i)\right]\right] \rightarrow h_{i+1, j} \\
& P_{3}:\left[\left(h_{i j} \leq h_{i, j+1}\right) \& \neg\left(h_{i, j-1} \rightarrow h_{i j}\right) \&[(j-1)>0]\right] \rightarrow h_{i, j-1} \\
& P_{4}:\left[\left(h_{i j} \leq h_{i-1, j}\right) \& \neg\left(h_{i-1, j} \rightarrow h_{i j}\right) \&[(i-1)>0]\right] \rightarrow h_{i-1, j} \\
& P_{5}:\left[\left(\neg P_{1} \& \neg P_{2} \& \neg P_{3} \& \neg P_{4}\right) \&[(j+1)<\max j] \rightarrow\left(h_{i j} \rightarrow h_{i, j+1}\right)\right. \\
& P_{6}:\left[\left(\neg P_{1} \& \neg P_{2} \& \neg P_{3} \& \neg P_{4}\right) \&[(i+1)<\max i] \rightarrow\left(h_{i j} \rightarrow h_{i+1, j}\right)\right.
\end{aligned}
$$

The given rules are called productions [1,2], and symbols $i, j$ mean numbers of single geometric primitives the image fragment $G_{i}$ is divided into, $h_{i j}$ means the value of change of the chosen parameter within a single graphic primitive. The sequence of productions $P_{1}, P_{2}, P_{3}, P_{4}, P_{5}, P_{6}$ determines priorities of their usage. 
An example of implementing a fragment of the scanning strategy, that describes transitions between fragments $G_{i}$, can be a set of the following productions:

$$
\begin{aligned}
& P_{7}:\left[\left(h_{i j} \notin G_{k+1}\right) \&\left(h_{i+1, j} \in G_{k+1}\right) \&\left(\left(i_{-} 1\right)<\max i\right)\right] \rightarrow\left(h_{i, j} \rightarrow h_{i+1, j}\right) \\
& P_{8}:\left[\left(h_{i j} \notin G_{k+1}\right) \&\left(h_{i, j+1} \in G_{k+1}\right) \&((j+1)<\max j)\right] \rightarrow\left(h_{i j} \rightarrow h_{i, j+1}\right) \\
& P_{9}:\left[\left(h_{i j} \notin G_{k+1}\right) \&\left(h_{i+1, j} \in G_{k+1}\right) \&(i=\max i) \&((j+1)<\max j)\right] \rightarrow\left(h_{i j} \rightarrow h_{i, j+1}\right) \\
& P_{10}:\left[\left(h_{i j} \notin G_{k+1}\right) \&(i=\max i) \&(j=\max j)\right] \rightarrow \text { end } . \\
& P=\left\{P_{1}, \ldots, P_{10}\right\} .
\end{aligned}
$$

\section{Defining the parameters of a steganosystem and graphic images}

A sign that characterizes a degree of relation between image fragments can be interpreted by steganosystem parameters in the following way. Let us assume that between two fragments of an image $\varphi_{i}$ and $\varphi_{k}$ there is an information relation. This means that the part of the image that consists of these two fragments represents a certain semantic fragment of the whole image. If this relation has changed or disrupted for some reasons, this can lead, and in most cases does lead, to violation of image semantics within its current part. This, in turn, leads to change of invisibility degree of modifications performed in fragments in order to introduce information in the corresponding environment. To use this sign, we have to choose a way to describe the corresponding relations. This description can be based on analysis of graphic elements that compose the image or image fragments, or on using interpretation of image elements, that has to accompany an arbitrary image, except for images that are abstract pieces of art, interpreting which is ambiguous and rather specific.

In the first case, this relation is established on the basis of analysis of graphic elements that are continued in the adjacent image fragment, or analysis of graphically represented relations between single graphic elements. It is obvious that a way to conduct such analysis depends on the image nature. If the image is typically rich in various colors, this relation can represent color transfers between selected fragments. These transfers can have various degree of smoothness within the color palette, the direction of color change in the picture space between two fragments can vary, and because of that, we can talk about graphic components that are defined by boundaries of color change and so on.

In the second case, relation between fragments is defined on the basis of analysis of interpretation descriptions of single components that are located in two adjacent image fragments and, first of all, on the basis of analysis of those parts of interpretation description that represent relations between the corresponding elements. 
Protection of a control system of a technical object from negative influence... Ochrona systemu sterowania obiektem technicznym przed negatywnym wptywem...

Regardless of the above-mentioned cases, there is a possibility to formally describe these relations between elements of adjacent fragments. This formal description will be a certain approximation of relations that can be described by the corresponding tools. The most generic tools to describe this relation are tools of mathematical logic $[3,4]$. At the level of general description of a relation degree, that is ensured by tools of mathematical logic, tasks exist that are caused by possibilities of the corresponding tools and has their own interpretation within a sign of degree of interpretation relation between single image fragments. Among these tasks there are the following:

- tasks of inconsistency of a system of a logic description of relations between the image fragments;

- task of completeness of a logic description;

- task of defining the description part which can be interpreted as an axiom system, and the part of a system of a logic description which can be interpreted by logic formulae, that can be deduced from the part interpreted as an axiom system;

- because of the last task, a task arises of generating rules of output that represent semantic interpretation of image fragments, of the whole image, that are an extension of a system of output rules.

Extending the system of output rules is known in theory of mathematical logic, for instance, Gentzen system of output rules, Gilbert system of output rules and others [5].

\section{Building a trajectory of scanning of a graphic image}

When building the scanning trajectory, situations can occur when scanning will not be able to be finished successfully. Among these situations are the following cases:

- cycles appear in the scanning trajectory;

- dead-end situations occur;

- the process of forming the image scanning trajectory aborts early;

- non-full coverage of image fragments and geometric primitives by the scanning trajectory.

Appearance of cycles in the scanning trajectory is critical for implementing the process of building the scanning trajectory. Possibility of cycle appearance in the cycle trajectory is closely related to rules of trajectory forming. Let us review the following statement.

Statement 1. If a production system $P$ is not contradictory in the field $\operatorname{grad}(U, B)$, then there is no cycling in the scanning trajectory $D$.

Occurrence of one or another situation during the building of the scanning trajectory is caused, first of all, by a process of forming of the corresponding trajectory. 
Thus, we can talk about dynamic nature of occurrence of dead-end situations. In this case, "dynamic" term means not process dependency on time, but dependency of the building process at each single step of forming the next transition on the configuration of already existing trajectory part in the area of building the next elementary transition in the scanning trajectory.

Before reviewing algorithms of choosing the trajectory of placement of information message elements, that is built on the basis of sign regarding the degree of information relation, we have to review the relation of this degree to parameters that characterize a steganosystem $[6,7]$.

To describe the picture, concepts of richness of single fragments of a graphic image are used. Let us introduce the following definition.

Definition 1. The richness $v$ of an image fragment $h_{i}$ will be understood as a number of elements of a graphic image that falls into the given fragment $h_{i}$. In order for the definition to be constructive, let us form an algorithm of calculating the value of richness $\mu$ of an image fragment $h_{i}$.

Algorithm (A1) of determining the richness $v_{\mathrm{i}}\left(\mathrm{h}_{\mathrm{i}}\right)$.

1). A net is placed over the fragment $h_{\mathrm{i}}$, the number of net cells defines $v=\max$.

2). A number is calculated of the net cells where at least one part of components of graphic image elements exists, then $\mathrm{x}_{\mathrm{i}}=1$, if in cell $i$ there is a graphic image element and vice versa. Thus, $v_{i}\left(h_{i}\right)=\sum_{i=1}^{m} x_{i}$.

Obviously, the more the number of cells $m$ in the net that is put over the image fragment, the more the precision of determining the richness degree $\mu$ of a single fragment $h_{i}$ can be. Let us assume that the basic parameters that characterize a steganosystem are the following:

- parameters of invisibility of modifications $\eta$ that were caused by introducing elements of an information fragment into a graphic image,

- parameter $\mathcal{X}$, that characterizes steganogram resistance regarding technological transformations of a graphic digital environment that are foreseen during transfer of digital files by channels of a computer network,

- parameter that characterizes the carrying capacity of a steganochannel $\lambda$,

- parameter that characterizes the degree of reversibility of a general functioning algorithm of a steganosystem $\xi$.

Invisibility degree is defined on the basis of data of psychological research of human eye mechanisms. Because the parameter $\eta$ depends on the whole set of factors that characterize the graphic image, simplified images are used in psychological research, for example, images looking like nets, relating to which sensitivity thresholds of the vision system are determined to changes in the graphic image. Images that are chosen for these researches are formed so that their invisibility threshold was minimal. 
Protection of a control system of a technical object from negative influence... Ochrona systemu sterowania obiektem technicznym przed negatywnym wptywem...

Thus, for real images, which have the whole set of factors that lead to increase of this threshold, results of experimental data can be used, obtained on test images. In this case, the invisibility degree, measured corresponding to algorithm A1, will have a certain margin.

Basing on data of psycho-physiological research of the human vision system [8,9], let us assume that the value of invisibility threshold of changes in a graphic image is affected by graphic richness of an image or its fragments. Moreover, let us assume that the following relation exists between $\eta$ and $v$ :

$$
\eta=\alpha v+\Delta \eta,
$$

where $\alpha$ is a matching coefficient greater than one, $\Delta \eta$ is the invisibility threshold defined on a test graphic image.

If an image is divided into rectangular fragments, the richness degree is a local degree of a single cell of an image fragment. In this case, this degree is similar to the local degree of clearness of a single cell, and the algorithm of building the element placement trajectory $\varphi_{i}(I)$ matches the algorithm of choosing the trajectory, used in a graphic method of choosing the image fragment sequence for introducing $\varphi_{i}(I)$.

Using this sign for preliminary choice of fragments gives wider possibilities in choosing optimal places for storing elements $\varphi_{i}(I)$ from the point of view of other parameters that can be used in a steganosystem. It is known that among the most visible ways of distortions are distortions that affect the image semantics or lead to its change. A description of the image semantics on a basic level can be approximated by logical formulae, each of which describes a single semantic fragment, while the rules of uniting single logical formulae, that will be written as $\psi_{\mathrm{i}}$, into a sequence are formed on the basis of semantic interpretation of image elements, and this sequence corresponds to the natural order of image inspection, followed by the human vision system.

A common scheme of this inspection order lies in the following: firstly, the most significant semantic fragments are inspected, followed by less significant semantic fragments. This procedure is split into stages that represent the significance degree of a single fragment. Based on this, we have to move from the richness degree of a single cell of a net, that divides the image into separate fragments, to fragments that store single semantic elements of the image. Fragments of the first type will be called technical fragments and written as $\varphi(d)$, while the fragments of the second type will be written as $\varphi(c)$ and called semantic fragments. Moving from $\varphi(d)$ to $\varphi(c)$ at the first step or the first stage will be implemented on the basis of detecting the continuing image elements from one $\varphi_{i}(d)$ to another, adjacent $\varphi_{i+1}(d)$. These continuations will be written as $\varphi_{\mathrm{i}}(\mathrm{d}) \rightarrow \varphi_{\mathrm{i}+1}(\mathrm{~d})$. An algorithm of detecting the 
continuing graphic elements between $\varphi(d)$ is based on search of points related to a single image fragment at the boundary of $\varphi(d)$. If such a point exists, we only have to check if this point is the last point of the element $d_{i}^{j}$, or if the fragment $\varphi_{i+1}(\mathrm{~d})$ has its continuation $d_{i+1}^{j}$. If such continuation exists, the following can be written:

$$
f\left[\varphi_{i}\left(d_{i}^{j}\right), \varphi_{i+1}\left(d_{i}^{j}\right)\right]=\varphi_{i}\left(d_{i}^{j}\right) \rightarrow \varphi_{i+1}\left(d_{i+1}^{j}\right)
$$

This procedure is continued until it turns out that the fragment $\varphi_{i+k}$ is the last one for the element $d^{j}$.

Besides, this procedure is extended by representing the change of direction of the next continuing element $d^{j}$.

If a rectangular net is chosen as $\varphi(\mathrm{d})$, directions change at $90^{\circ}$ in two different sides, which in general is written by the relation:

$$
f\left[\varphi_{i}\left(d_{i}^{j}\right), \varphi_{i+1}\left(d_{i}^{j}\right)\right]=\varphi_{i}\left(d_{i}^{j}\right) \rightarrow \pm \alpha_{i+1} \varphi_{i+1}\left(d_{i+1}^{j}\right),
$$

where $\alpha_{i+1}$ is an angle of transition between two fragments $\varphi_{i}\left(d_{i}\right)$. In case of using rectangular nets, $\alpha_{i}$ can have $+90^{\circ}$, which means a clockwise turn, and $-90^{\circ}$ angle, which means a counter-clockwise turn. Thus, the relation will be written as follows:

$$
f\left[\varphi_{i}\left(d_{i}^{j}\right), \varphi_{i+1}\left(d_{i}^{j}\right)\right]=\varphi_{i}\left(d_{i}^{j}\right) \rightarrow(\uparrow \oplus \downarrow) \varphi_{i+1}\left(d_{i+1}^{j}\right) .
$$

Detecting semantic components can be based on tracing the contrast lines, tracing the lines of color change and other elements that help to recreate semantic components in a graphic image. To increase the precision of approximation of semantic components, regular polygons can be used as a net for image space at $\varphi(d)$, that ensure full space coverage, for example, hexagons.

After defining the continuous semantic image elements, the steganosystem has to use semantic vocabularies. Transition from $\varphi(d)$ to $\varphi(c)$ is written as follows:

$$
\left[\varphi_{i 1}\left(d_{i 1}^{j}\right) \rightarrow \downarrow \varphi_{i 2}\left(d_{i 2}^{j}\right) \rightarrow \ldots \rightarrow \uparrow \varphi_{i k}\left(d_{i k}^{j}\right)\right]=\left[\varphi\left(d_{i}^{j}\right) \rightarrow \varphi\left(c_{j}\right)\right] .
$$

Semantic vocabularies are structures divided by types and classes of graphic elements that describe semantics of the corresponding elements. A semantic description of graphic elements of a type $\varphi(c)$ is logical formulae that describe possible relations between single $\varphi\left(\mathrm{c}_{\mathrm{i}}\right)$. Unlike tools of classical logic, in this case, extended functions of logical relations are used, that allow to take into account mutual placement of single elements $c_{i}$ at the picture space. To represent such placement, predicates of directions of element continuations are used. 
Protection of a control system of a technical object from negative influence...

Ochrona systemu sterowania obiektem technicznym przed negatywnym wptywem...

These predicates are the following:

- predicate of mutual placement orientation of an adjacent semantic element @;

- predicate of consistent matched placement of two semantic elements \#;

- predicate of contradicting relations between single semantic elements $\$$.

An example of a logical function that describes a semantic fragment of a graphic image that uses the corresponding predicated can be the following expression:

$$
Q_{i}=\left\{\left[\left[C_{i} \& \#\left(C_{k}\right)\right] \vee\left[C_{i+1} \& @\left(C_{j}\right)\right]\right] \rightarrow \$\left(C_{i}, C_{j}\right),\right.
$$

where $Q_{i}$ is a semantic fragment of the graphic image. A predicate @ $\left(\mathrm{C}_{\mathrm{j}}\right)$ means that in $\mathrm{Q}_{\mathrm{i}}$ only such mutual placement of two semantic components $\mathrm{C}_{\mathrm{i}}$ and $\mathrm{C}_{\mathrm{i}+1}$ is allowed, that are defined by given tables of acceptable placements stored in the semantic vocabulary $S_{c}$.

In case of absence of @, the mutual placement of $\mathrm{C}_{\mathrm{i}}$ and $\mathrm{C}_{\mathrm{i}+1}$ is arbitrary. A predicate $\#\left(C_{k}\right)$ means that $C_{i}$ and $C_{k}$ have to be consistent corresponding to the conditions of subject interpretation $\mathrm{J}(\mathrm{Q})$ in the vocabulary $\mathrm{S}_{\mathrm{c}}$. A predicate $\$\left(\mathrm{C}_{\mathrm{ij}}, \mathrm{C}_{\mathrm{j}}\right)$ means that elements $\mathrm{C}_{\mathrm{i}}$ and $\mathrm{C}_{\mathrm{j}}$ can be adjacent in a semantic fragment only in the case when their matching is not forbidden by the table of unacceptable matchings, located in the vocabulary $S_{c}[10]$.

The above-mentioned way of extending the logic of describing semantic fragments and image semantics in general allows to distinguish semantically significant fragments of an image $Q_{i}$. This means that information elements from $\varphi(I)$ have to be, first of all, placed in semantically significant fragments. Significance of semantic fragments $\varphi\left(c_{i}\right)$, within this approach, is determined by the richness degree of the whole semantic fragment in general.

One of the main steganosystem parameters is resistance of a steganosystem to technological transformations of graphic files $\aleph(Q)$. This means that a steganosystem $S_{C}$ can form such a steganogram in $Q_{i}$ that will not be distorted to an unacceptable degree by such technological transformations as image compression, image filtering and other transformations directed towards solving technologic tasks of optimal functioning of a computer network. These criteria are the following:

- minimizing the time for data transfer by connection channels, implemented in computer networks,

- decreasing the influence of noises and obstacles that exist in networks and are caused by technical tools of implementing the computer network and system software tools. 
When there is a possibility to determine the semantic significance of image fragments, it becomes possible to choose for placement of elements $\varphi_{i}(I)$ in the segments $\varphi\left(c_{i}\right)$ that have maximal semantic significance. Thus, it is possible to achieve increasing value of the parameter $\aleph$ of the corresponding steganosystem ( $S S$ ).

\section{Summary}

The paper contains the basis for reasonability of using steganographic methods of hiding information to withstand the negative influence of human factor on a CTO control system.

Methods were developed for analysis of graphic digital environments, using which steganosystems are oriented towards. At the first stage of analysis of a graphic digital environment, methods of its scanning are researched, thanks to which it becomes possible to choose in the graphic environment the most suitable places for storing the message elements.

This suitability is defined on the basis of using the chosen parameter of a graphic image, relating to which the invisibility parameter is ensured of a message that is introduced in a digital environment.

A relation is researched between steganosystem parameters and parameters of graphic images, which gives the possibility to increase efficiency of algorithms of hiding messages at the expense of calculation of relation between image parameters that are formed on the basis of features of image perception by human vision system, and parameters that characterize the functioning process of a steganosystem.

\section{References}

[1] Shenfield J. Mathematical logic. - Moscow: Nauka, 1975, -527 p.

[2] Boolos J., Jeffrey R. Computability and logic. - Moscow: Mir, 1994, - 396 p.

[3] Curry H. Foundations of mathematical logic. Moscow: Mir, 1969.

[4] Ershov Y.L.,Palyutin Y.A. Mathematical logic. Moscow: Nauka, 1979. - 320 p.

[5] Takeuchi G. Theory of proof. Moscow: Mir, 1978. - 412 p.

[6] Afanasyeva O.Y., Y.M.Korostil. Features of using parameters of steganosystems.// Collected studies. Institute of problems of modeling in energetics (IPME NSA of Ukraine). - Kyiv 2006. - Issue 32. P. 158-161.

[7] Afanasyeva O.Y., Sabat V.I. Method of describing graphic images in a steganosystem and semantic conflicts.// Collected studies. Institute of problems of modeling in energetics (IPME NSA of Ukraine). - Kyiv 2008. Issue. 45. P. 132-137.

[8] Ilyin Y.P. Motivation and motives. - Saint-Petersburg: Piter, 2000. 
Protection of a control system of a technical object from negative influence...

Ochrona systemu sterowania obiektem technicznym przed negatywnym wptywem...

[9] Mlodkowski J. Aktywnosc wizualna czlowieka. - Warszawa: PWN, 2000.

[10] Knut D. Art of programming for computers. Basic algorithms. Moscow: Mir. $-730 \mathrm{p}$.

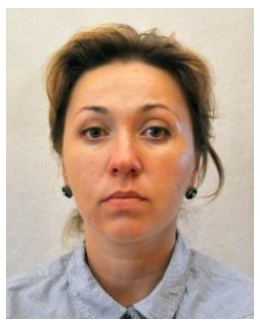

Olesia Afanasieva, Doctor of sciences, prof. Pedagogical University in Krakow.Specializes in the following scientific research fields: steganography hiding of messages in digital environments of various types, safety of complex technical objects, information systems security methods, experimental data analysis with cognitive graphics means. 